\title{
Occurrence of traumatic brain injury due to short falls with or without a witness by a nonrelative in children younger than 2 years
}

\author{
Shunsuke Amagasa, MD, PhD, Satoko Uematsu, MD, PhD, and Satoshi Tsuji, MD \\ Division of Emergency and Transport Services, National Center for Child Health and Development, Tokyo, Japan
}

\begin{abstract}
OBJECTIVE There is disagreement about the occurrence of severe traumatic brain injury, especially subdural hematoma, caused by short falls in very young children. To verify intracranial injury due to these falls and examine its characteristics, the authors compared infants and toddlers with head trauma witnessed by a nonrelative with those whose injuries were not witnessed by a nonrelative.
\end{abstract}

METHODS The authors retrospectively reviewed clinical records of children younger than 2 years with head trauma due to a short fall who visited the emergency department of the National Center for Child Health and Development in Japan between April 2015 and March 2018. Patients were classified into two groups: falls that were witnessed by a nonrelative and falls not witnessed by a nonrelative. The authors compared the age in months, sex, mechanism of injury, fall height, prevalence rate of intracranial injury, skull fracture, type of traumatic brain injury, retinal hemorrhage, rib or long-bone fracture, and outcomes between patients whose fall was witnessed by a nonrelative and those whose fall was not witnessed by a nonrelative.

RESULTS Among 1494 patients included in the present analysis, 392 patients were classified into the group of falls witnessed by a nonrelative, and 1102 patients were classified into the group of falls that were not witnessed by a nonrelative. The prevalence rates of intracranial injury, skull fracture, epidural hematoma, and subarachnoid hemorrhage were equal between the groups. The prevalence rate of subdural hematoma in the group whose falls were witnessed by a nonrelative was significantly lower than that of the other group $(p=0.027)$. There were no patients with subdural hematoma, retinal hemorrhage, or neurological sequelae in the group whose fall was witnessed by a nonrelative.

CONCLUSIONS Subdural hematoma, retinal hemorrhage, and neurological sequelae due to short falls were not seen after witnessed falls in the present study.

https://thejns.org/doi/abs/10.3171/2020.6.PEDS20314

KEYWORDS child; infant; abusive head trauma; subdural hematoma; retinal hemorrhage

$\mathrm{H}$ EAD trauma is a leading cause of emergency department visits for young children. ${ }^{1}$ The major cause of this head trauma is short falls, such as a fall from a couch or bed, or falling while pulling to a standing position. ${ }^{2}$ Many studies have stated that falls from less than 3-4 feet seldom cause severe head injury; ${ }^{3-6}$ however, we have encountered pediatric cases with severe head injury even though the history of injury obtained from the caregiver was supposedly a mild cause.

Among head trauma in infants and young children, inflicted brain injury is the leading cause of neurological sequelae and death. ' Severe head injury, particularly subdural hematoma (SDH), with a history of a short fall is deeply concerning for abusive head trauma (AHT) ${ }^{8,9} \mathrm{Al}-$ though many studies have stated that severe head injury due to a short fall is very unlikely ${ }^{3-6}$ and the reliability of the history obtained from the caregivers may be low in severe head injury, ${ }_{10,11}^{11}$ several studies have reported that short falls could cause SDH. ${ }^{12-16}$ Despite the fact that many studies have reported findings suggesting AHT, such as $\mathrm{SDH}$, retinal hemorrhage, and cerebral edema, ${ }^{8,9,17-20}$ these findings are not considered the gold standard. ${ }^{21}$ Moreover, most AHT studies have a problem of circularity bias because the diagnosis of AHT and accidental trauma is based on these findings. ${ }^{22}$ The diagnosis of AHT remains challenging, and we sometimes face a challenge determin-

ABBREVIATIONS AHT = abusive head trauma; EDH = epidural hematoma; $I C I=$ intracranial injury; $S A H=$ subarachnoid hemorrhage; $S D H=$ subdural hematoma. SUBMITTED April 22, 2020. ACCEPTED June 1, 2020.

INCLUDE WHEN CITING Published online September 11, 2020; DOI: 10.3171/2020.6.PEDS20314. 
ing whether the infants or young children have sustained an intracranial injury (ICI) from an unfortunate accident or as a consequence of abuse.

To verify intracranial injury due to short falls and examine the characteristics of head trauma due to short falls, investigation of head trauma with a nonrelative witness is required. ${ }^{23}$ We therefore compared children younger than 2 years with head trauma witnessed by a nonrelative with those whose injuries were not witnessed by a nonrelative.

\section{Methods \\ Patients}

We retrospectively reviewed the clinical records of children younger than 2 years with head trauma due to short falls who visited the emergency department of the National Center for Child Health and Development in Japan between April 2015 and March 2018. We excluded children with hemorrhagic or bone diseases, those taking antiplatelet agents or anticoagulant agents, and cases lacking information about the location where the children were injured.

\section{Measurement and Definitions}

Patients were classified into two groups based on whether the fall was witnessed by a nonrelative (fall in a public space; nonrelative witness of the accident was supposedly present) or was not witnessed by a nonrelative (fall in a private space; nonrelative witness supposedly absent).

We compared age in months, sex, mechanism of injury, fall height, prevalence rate of ICI, skull fracture, type of traumatic brain injury (SDH, epidural hematoma [EDH], subarachnoid hemorrhage [SAH], and brain edema), retinal hemorrhage, rib or long-bone fracture, and outcomes between patients whose falls were witnessed by a nonrelative and those for whom the fall was not witnessed by a nonrelative. Additionally, we compared the available head CT scans between the groups.

The information about the accident site was primarily determined by the history given by the caregivers to a physician in the emergency department. In cases with inconsistencies between the history and the severity of injury, we additionally verified the history by hearing from the caregivers. Patients whose trauma occurred in a private space, but with a nonrelative witness, were classified as having a fall witnessed by a nonrelative. A short fall was defined as a fall from less than 3 feet, falling from a standing or sitting position, and other minor head trauma (e.g., being struck by a toy, bumping against the wall). A fall from a shorter adult's arm and a fall from a stationary bicycle child seat were defined as a fall from less than 3 feet. A fall from a taller adult's arm was defined as a non-short fall because the fall height from a taller adult's arms would be greater than 3 feet. A shorter person's falling while the child was being carried and a stationary bicycle's falling while the child was sitting in the child seat were defined as other minor head trauma. In stairway falls, 1 step was defined as $20 \mathrm{~cm}$. The mechanism of injury was divided into fall (a fall or vertical fall), falling from a standing or sitting position, and other. Neurological sequelae (Pediatric Cerebral Performance Category $\geq 2)^{24}$ at 6 months after trauma and death were measured as outcomes.
At our institution, head CT scanning is performed according to the Pediatric Emergency Care Applied Research Network head trauma prediction rules. ${ }^{1}$ The children who are characterized as being at intermediate risk and do not undergo a head CT scan are observed in the hospital for several hours and revisit our emergency department the following day. In addition, we ask all caregivers of the patients after head trauma to return to the hospital when the patients have symptoms. All imaging findings were assessed by a radiologist.

\section{Statistical Analysis}

The Mann-Whitney U-test was used to compare age in months and fall height. The chi-square test or Fisher's exact test was used to compare sex, mechanism of injury, prevalence rate of ICI, skull fracture, type of traumatic brain injury, retinal hemorrhage, rib or long-bone fracture, and outcomes.

All statistical tests were two-sided, and an $\alpha$ level of 0.05 was considered to indicate significance. All data analyses were performed using IBM SPSS statistical software version 24 (IBM Corp.).

\section{Results}

A total of 1530 patients younger than 2 years with head trauma due to a short fall visited our emergency department. After the exclusion of 12 cases with hemorrhagic or bone diseases or who were taking antiplatelet agents or anticoagulant agents, and 24 cases lacking information about the location where the child was injured, 1494 patients were included in the present analysis (Fig. 1). A total of 392 patients were classified into the group in which the fall was witnessed by a nonrelative, and 1102 patients were classified into the group in which the fall was not witnessed by a nonrelative.

The patient age in the group whose fall was witnessed by a nonrelative was significantly higher than that in the group whose fall was not witnessed by a nonrelative ( $p$ $<0.01$ ) (Table 1). Among mechanisms of injury, the fall rate of patients with witnessed falls was significantly lower than that in patients whose fall was not witnessed by a nonrelative $(\mathrm{p}<0.01)$. The prevalence rates of ICI, skull fracture, $\mathrm{EDH}$, and SAH were equal between the two groups (Table 2). The prevalence rate of SDH in patients whose fall was witnessed by a nonrelative was significantly lower than that in patients whose fall was not witnessed by a nonrelative $(\mathrm{p}=0.027)$, and there were no patients with $\mathrm{SDH}$, retinal hemorrhage, or neurological sequelae in the group whose fall was witnessed by a nonrelative. All patients with neurological sequelae had SDH and retinal hemorrhage, and all patients with retinal hemorrhage had SDH. Severe bilateral retinal hemorrhage (3 patients), severe unilateral retinal hemorrhage (1 patient), and mild unilateral retinal hemorrhage (1 patient) were observed.

Among 1494 patients, 139 (9.3\%) patients underwent head CT scanning. Of these, in 30 patients the fall was witnessed by a nonrelative and in 109 patients the fall was not witnessed by a nonrelative. The prevalence rate of SDH in the witnessed fall group was significantly lower than that 


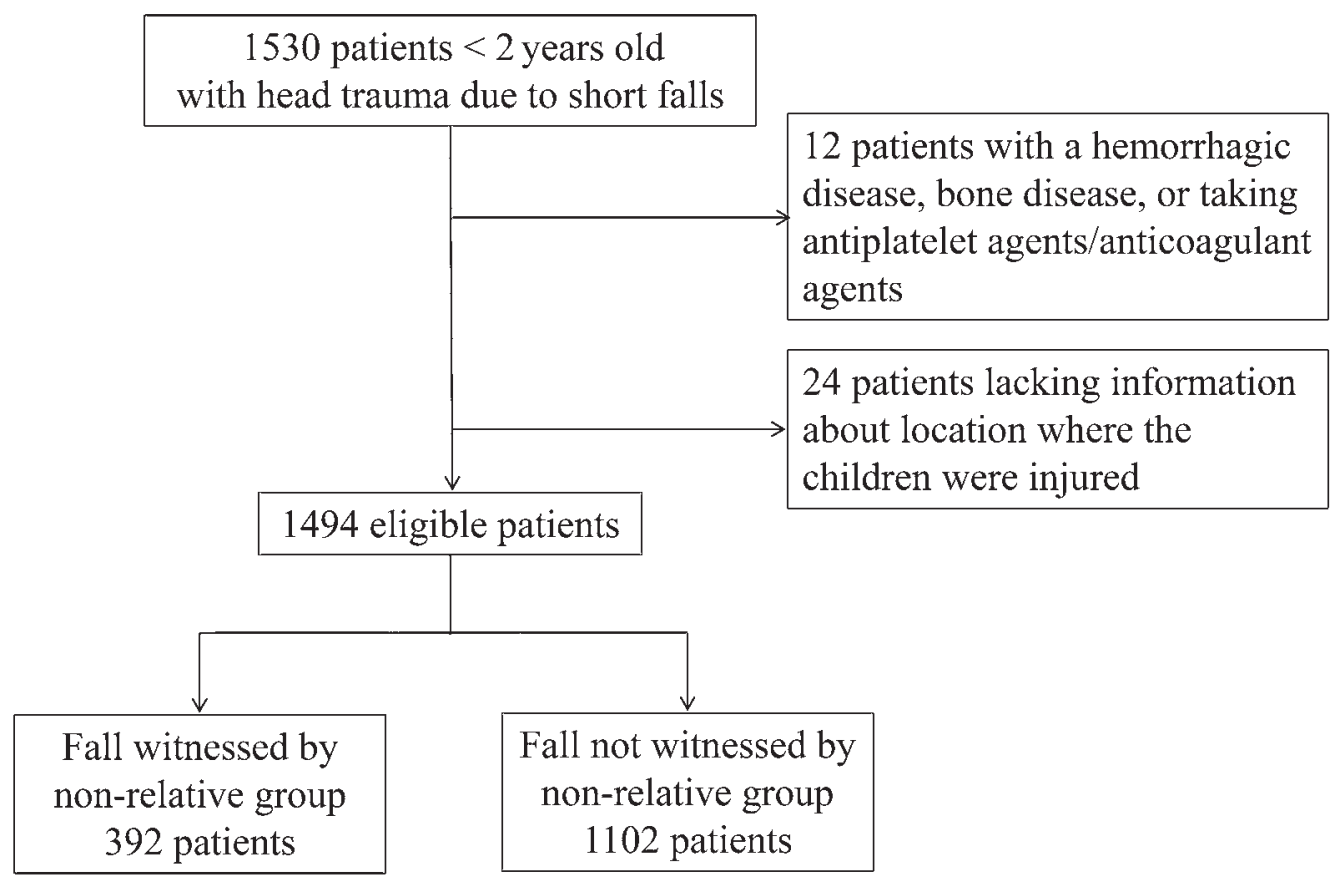

FIG. 1. Study flow chart.

in the group with an unwitnessed fall among patients who underwent head CT scanning $(\mathrm{p}=0.040)$ (Table 3).

\section{Discussion}

The present study retrospectively examined the records of 1494 patients younger than 2 years with head trauma due to short falls and compared the children who had head trauma occurring with and without witness by a nonrelative. We found that, although low in frequency, ICI and skull fracture can occur in short falls and that there are no differences in the prevalence rate of ICI and skull fracture between witnessed falls and falls not witnessed by a nonrelative; however, children with SDH, retinal hemorrhage, or neurological sequelae were not observed in the falls that were witnessed by a nonrelative.

Many studies over the past several decades have reported that no serious injuries occur in children who fall from less than 3-4 feet, ${ }^{3-6}$ and a systematic review reported that the mortality rate for a fall from less than 5 feet was less than 0.5 deaths per 1 million young children per year. ${ }^{3}$ On the other hand, several studies have reported that there are children with SDH due to short falls who could have retinal hemorrhage. ${ }^{12-16}$ Although a case series reported in 2018 provided information about an investigation of AHT, ${ }^{12}$ the investigation of AHT was not conducted in a case series reported in $1984,,^{13}$ and two single case reports and one case series have insufficient information about the exclusion of AHT.14-16 Additionally, a systematic review reported that there was insufficient evidence with which to assess the accuracy of the triad of SDH, retinal hemorrhage, and encephalopathy, which has been described as being specific to shaken baby syndrome, while attempting to identify inflicted shaking. ${ }^{25,26}$ Although this report has been used for legal defense arguments, the report has received much criticism for using incorrect methods. ${ }^{27-31}$ There are arguments against the diagnosis of AHT in clinical practice and the courts; however, there is weak evidence for severe SDH due to short falls.

TABLE 1. Demographics and mechanism of injury in the study population

\begin{tabular}{lccc}
\hline & $\begin{array}{c}\text { Fall Witnessed by } \\
\text { Nonrelative }(\mathrm{n}=392)\end{array}$ & $\begin{array}{c}\text { Fall Not Witnessed by } \\
\text { Nonrelative }(\mathrm{n}=1102)\end{array}$ & $\mathrm{p}$ Value \\
\hline Age in mos, median (IQR) & $16(10-20)$ & $11(6-17)$ & $<0.01$ \\
\hline Male sex, $\mathrm{n}(\%)$ & $214(54.6)$ & $621(56.4)$ & 0.547 \\
\hline Mechanism of injury, $\mathrm{n}(\%)$ & & & \\
\hline Fall & $163(41.6)$ & $655(59.4)$ & \\
\hline Fall from sitting or standing position & $134(34.2)$ & $309(28.0)$ & \\
\hline$\quad$ Other & $95(24.2)$ & $138(12.5)$ & \\
\hline Fall height in cm, median (IQR) & $50(50-70)$ & $50(40-70)$ & 0.207 \\
\hline
\end{tabular}


TABLE 2. Comparisons of characteristics of traumatic brain injury, retinal hemorrhage, rib or long-bone fracture, and outcomes

\begin{tabular}{lccc}
\hline & \multicolumn{2}{c}{ No. of Patients (\%) } & \\
\cline { 2 - 3 } & $\begin{array}{c}\text { Fall } \\
\text { Witnessed by } \\
\text { Nonrelative } \\
(\mathrm{n}=392)\end{array}$ & $\begin{array}{c}\text { Fall Not } \\
\text { Witnessed by } \\
\text { Nonrelative } \\
(\mathrm{n}=1102)\end{array}$ & \\
\hline $\mathrm{ICl}$ & $7(1.8)$ & $25(2.3)$ & 0.571 \\
\hline $\mathrm{SDH}$ & 0 & $14(1.3)$ & 0.027 \\
\hline EDH & $6(1.5)$ & $11(1.0)$ & 0.409 \\
\hline SAH & $2(0.5)$ & $5(0.5)$ & $>0.99$ \\
\hline Cerebral edema & 0 & $2(0.2)$ & $>0.99$ \\
\hline Linear skull fracture & $11(2.8)$ & $34(3.1)$ & 0.781 \\
\hline Depressed skull fracture & 0 & $4(0.4)$ & 0.578 \\
\hline Retinal hemorrhage* & 0 & $5(0.5)$ & 0.334 \\
\hline Rib or long-bone fracture & 0 & 0 & \\
\hline Neurological sequelae & 0 & $3(0.3)$ & 0.571 \\
\hline Death & 0 & 0 & \\
\hline
\end{tabular}

* Of patients who underwent fundoscopy, 7 had their fall witnessed by a nonrelative and 34 did not have their fall witnessed by a nonrelative. † Of patients who underwent a skeletal survey, 6 had their fall witnessed by a nonrelative and 30 did not have their fall witnessed by a nonrelative.

In the present study, although the prevalence rates of $\mathrm{EDH}, \mathrm{SAH}$, and skull fracture were almost equal between the falls witnessed by a nonrelative and those not witnessed by a nonrelative, there is an apparent difference in some of the characteristics. Children with SDH, retinal hemorrhage, and neurological sequelae were observed only in the group whose falls were not witnessed by a nonrelative, and the prevalence rate of SDH in falls not witnessed by a nonrelative was significantly higher than that of witnessed falls. From these data, SDH and retinal hemorrhage due to short falls were not observed in the presence of nonrelative witnesses. In a systematic review, SDH and retinal hemorrhage were strongly associated with AHT (OR 8.92, 95\% CI 6.77-11.74; and OR 27.12, 95\% CI 15.70-46.84, respectively). ${ }^{8}$ In another systematic review regarding neuroradiological findings, SDH was also strongly associated with AHT (OR 8.23, 95\% CI 6.14-11.04). ${ }^{9}$ Systematic reviews, criteria, and many studies reported that the findings of SDH and retinal hemorrhage have high specificity to AHT. ${ }^{8,9,17-20}$ Therefore, we should investigate possible AHT in cases with SDH and retinal hemorrhage due to short falls.

Many AHT studies have been conducted. We all are likely to run into a problem of misclassification and circular reasoning when we conduct a study in which children were divided into AHT and accidental head trauma and the two groups were compared..$^{22}$ In the present study, children were objectively classified according to the site of an accident to reduce the risk of misclassification and circular reasoning. Because of a lack of a confession or accusation of AHT, it is difficult to conclude that SDH in falls not witnessed by a nonrelative is AHT. However, in the objective classification, the findings of occurrence of
TABLE 3. Comparisons of characteristics of traumatic brain injury, retinal hemorrhage, rib or long-bone fracture, and outcomes among patients who underwent head CT scanning

\begin{tabular}{lccc}
\hline & \multicolumn{2}{c}{ No. of Patients (\%) } & \\
\cline { 2 - 3 } & $\begin{array}{c}\text { Fall } \\
\text { Witnessed by } \\
\text { Nonrelative } \\
(\mathrm{n}=30)\end{array}$ & $\begin{array}{c}\text { Fall Not } \\
\text { Witnessed by } \\
\text { Nonrelative } \\
(\mathrm{n}=109)\end{array}$ & p Value \\
\hline $\mathrm{ICI}$ & $7(23.3)$ & $25(22.9)$ & 0.963 \\
\hline $\mathrm{SDH}$ & 0 & $14(12.8)$ & 0.040 \\
\hline EDH & $6(20.0)$ & $11(10.1)$ & 0.204 \\
\hline SAH & $2(6.7)$ & $5(4.6)$ & 0.644 \\
\hline Cerebral edema & 0 & $2(1.8)$ & $>0.99$ \\
\hline Linear skull fracture & $11(36.7)$ & $34(31.2)$ & 0.570 \\
\hline Depressed skull fracture & 0 & $4(3.7)$ & 0.577 \\
\hline Retinal hemorrhage & 0 & $5(4.6)$ & 0.585 \\
\hline Rib or long-bone fracture & 0 & 0 & \\
\hline Neurological sequelae & 0 & $3(2.8)$ & $>0.99$ \\
\hline Death & 0 & 0 & \\
\hline
\end{tabular}

$\mathrm{SDH}$, retinal hemorrhage, and neurological sequelae only in the absence of a nonrelative witness may be important.

The current study has several limitations. First, this study divided children into groups based on whether or not the fall was witnessed by a nonrelative. There are cases in which the presence or absence of a nonrelative witness could not be substantiated. However, the nonrelative witnesses were examined in detail among cases with SDH resulting from suspected AHT; therefore, there were no cases with SDH in the presence of a nonrelative witness in the present data. Second, CT scans were obtained only in some patients. Although we have conducted head CT scans according to the criteria and adequately followed up the patients, there may have been asymptomatic SDH among those who did not undergo imaging. Additionally, although more than $90 \%$ of patients with ICI underwent fundoscopy and a skeletal survey, the rate of patients who underwent these evaluations was small among the eligible patients. Third, age distribution, characteristics of the surface on which the patient fell, and other aspects were not closely similar between the two groups. These differences have an ambiguous effect on outcomes. Finally, this study investigated cases from one institution over a limited period. Because of the limited number of cases, the data could not disprove the existence of SDH due to short falls.

\section{Conclusions}

$\mathrm{SDH}$, retinal hemorrhage, and neurological sequelae due to short falls were not seen after witnessed falls in the present study. Additional larger studies should be conducted regarding head trauma due to short falls in infants and young children.

\section{References}

1. Kuppermann N, Holmes JF, Dayan PS, et al. Identification of children at very low risk of clinically-important brain in- 
juries after head trauma: a prospective cohort study. Lancet. 2009;374(9696):1160-1170.

2. Hughes J, Maguire S, Jones M, et al. Biomechanical characteristics of head injuries from falls in children younger than 48 months. Arch Dis Child. 2016;101(4):310-315.

3. Chadwick DL, Bertocci G, Castillo E, et al. Annual risk of death resulting from short falls among young children: less than 1 in 1 million. Pediatrics. 2008;121(6):1213-1224.

4. Williams RA. Injuries in infants and small children resulting from witnessed and corroborated free falls. J Trauma. 1991; 31(10):1350-1352.

5. Lyons TJ, Oates RK. Falling out of bed: a relatively benign occurrence. Pediatrics. 1993;92(1):125-127.

6. Levene S, Bonfield G. Accidents on hospital wards. Arch Dis Child. 1991;66(9):1047-1049.

7. Parks SE, Kegler SR, Annest JL, Mercy JA. Characteristics of fatal abusive head trauma among children in the USA: 2003-2007: an application of the CDC operational case definition to national vital statistics data. Inj Prev. 2012;18(3): 193-199.

8. Piteau SJ, Ward MG, Barrowman NJ, Plint AC. Clinical and radiographic characteristics associated with abusive and nonabusive head trauma: a systematic review. Pediatrics. 2012; 130(2):315-323.

9. Kemp AM, Jaspan T, Griffiths J, et al. Neuroimaging: what neuroradiological features distinguish abusive from nonabusive head trauma? A systematic review. Arch Dis Child. 2011;96(12):1103-1112.

10. Amagasa S, Matsui H, Tsuji S, et al. Accuracy of the history of injury obtained from the caregiver in infantile head trauma. Am J Emerg Med. 2016;34(9):1863-1867.

11. Fujiwara T, Nagase H, Okuyama M, et al. Validity of caregivers' reports on head trauma due to falls in young children aged less than 2 years. Clin Med Insights Pediatr. 2010;4: $11-18$.

12. Atkinson N, van Rijn RR, Starling SP. Childhood falls with occipital impacts. Pediatr Emerg Care. 2018;34(12):837-841.

13. Aoki N, Masuzawa H. Infantile acute subdural hematoma. Clinical analysis of 26 cases. J Neurosurg. 1984;61(2):273280.

14. Fung EL, Sung RY, Nelson EA, Poon WS. Unexplained subdural hematoma in young children: is it always child abuse? Pediatr Int. 2002;44(1):37-42.

15. Denton S, Mileusnic D. Delayed sudden death in an infant following an accidental fall: a case report with review of the literature. Am J Forensic Med Pathol. 2003;24(4):371-376.

16. Gardner HB. A witnessed short fall mimicking presumed shaken baby syndrome (inflicted childhood neurotrauma). Pediatr Neurosurg. 2007;43(5):433-435.

17. Maguire S, Pickerd N, Farewell D, et al. Which clinical features distinguish inflicted from non-inflicted brain injury? A systematic review. Arch Dis Child. 2009;94(11):860-867.

18. Maguire SA, Kemp AM, Lumb RC, Farewell DM. Estimating the probability of abusive head trauma: a pooled analysis. Pediatrics. 2011;128(3):e550-e564.

19. Hymel KP, Armijo-Garcia V, Foster R, et al. Validation of a clinical prediction rule for pediatric abusive head trauma. Pediatrics. 2014;134(6):e1537-e1544.
20. Cowley LE, Morris CB, Maguire SA, et al. Validation of a prediction tool for abusive head trauma. Pediatrics. 2015; 136(2):290-298.

21. Duhaime AC, Christian CW. Abusive head trauma: evidence, obfuscation, and informed management. J Neurosurg Pediatr. 2019;24(5):481-488.

22. Vinchon M, de Foort-Dhellemmes S, Desurmont M, Delestret I. Confessed abuse versus witnessed accidents in infants: comparison of clinical, radiological, and ophthalmological data in corroborated cases. Childs Nerv Syst. 2010; 26(5):637-645.

23. Feldman KW, Bethel R, Shugerman RP, et al. The cause of infant and toddler subdural hemorrhage: a prospective study. Pediatrics. 2001;108(3):636-646.

24. Fiser DH. Assessing the outcome of pediatric intensive care. J Pediatr. 1992;121(1):68-74.

25. Lynøe N, Elinder G, Hallberg B, et al. Insufficient evidence for 'shaken baby syndrome' - a systematic review. Acta Paediatr. 2017;106(7):1021-1027.

26. Lynøe N, Elinder G, Hallberg B, et al. Is accepting circular reasoning in shaken baby studies bad science or misconduct? Acta Paediatr. 2017;106(9):1445-1446.

27. Choudhary AK, Servaes S, Slovis TL, et al. Consensus statement on abusive head trauma in infants and young children. Pediatr Radiol. 2018;48(8):1048-1065.

28. Debelle GD, Maguire S, Watts P, et al. Abusive head trauma and the triad: a critique on behalf of $\mathrm{RCPCH}$ of 'Traumatic shaking: the role of the triad in medical investigations of suspected traumatic shaking.' Arch Dis Child. 2018;103(6): 606-610.

29. Bilo RAC, Banaschak S, Herrmann B, et al. Using the table in the Swedish review on shaken baby syndrome will not help courts deliver justice. Acta Paediatr. 2017;106(7):10431045.

30. Levin AV. The SBU report: a different view. Acta Paediatr. 2017;106(7):1037-1039.

31. Strouse PJ. Shaken baby syndrome is real. Pediatr Radiol. 2018;48(8):1043-1047.

\section{Disclosures}

The authors report no conflict of interest concerning the materials or methods used in this study or the findings specified in this paper.

\section{Author Contributions}

Conception and design: Amagasa, Uematsu. Acquisition of data: Amagasa. Analysis and interpretation of data: Amagasa. Drafting the article: Amagasa. Critically revising the article: Uematsu, Tsuji. Reviewed submitted version of manuscript: all authors. Approved the final version of the manuscript on behalf of all authors: Amagasa. Statistical analysis: Amagasa.

\section{Correspondence}

Shunsuke Amagasa: National Center for Child Health and Development, Tokyo, Japan. amagasa0828@gmail.com. 